\title{
The association between exposure to secondhand smoke and psychological symptoms among Chinese children
}

\author{
Hui Wang ${ }^{1}$, Fei Li $i^{1}$, Yunting Zhang ${ }^{2}$, Fan Jiang ${ }^{3^{*}}$ and Jun Zhang ${ }^{1 *}$
}

\begin{abstract}
Background: The effect of secondhand smoke (SHS) exposure on child psychological problems remained inconclusive in previous studies. The aim of this study is to explore the association between SHS exposure and psychological symptoms in children.

Methods: This population-based cross-sectional survey used cluster random probability sampling and recruited children aged 6-13 years in 26 primary schools in Shanghai, China, in 2014. Duration of SHS exposure in children were categorized as none, $<1 \mathrm{~h} /$ day, 1-2 h/day, $\geq 3 \mathrm{~h} /$ day. Psychological symptoms were assessed by the parental version of the Strengths and Difficulties Questionnaire (SDQ). We used logistic regression to estimate the adjusted associations of SHS exposure with total SDQ and its specific domains. Multiple imputation was used for handling missing data.
\end{abstract}

Results: A total of 17,571 children completed this survey, with a response rate of $99.7 \%$. SDQ scores were available for 15,344 participants, of whom $20.9 \%$ were not exposed to SHS, $63.0 \%$ exposed for $<1 \mathrm{~h} /$ day, $10.4 \%$ for $1-2 \mathrm{~h} /$ day, and $5.7 \%$ for $\geq 3 \mathrm{~h} /$ day. Compared to children not exposed to SHS, SHS exposure was positively associated with total SDQ score: OR 1.42, 95\% confidence interval (Cl) 1.22 to 1.66 for SHS exposure < $1 \mathrm{~h} /$ day, OR 2.14, 95\% Cl 1.76 to 2.62 for $1-2 \mathrm{~h} /$ day and $\mathrm{OR} 2.53,95 \% \mathrm{Cl} 2.01$ to 3.18 for $\geq 3 \mathrm{~h} /$ day after adjusting for sex, age, mode of birth, family socio-economic status and place of birth. These associations did not vary by sex.

Conclusion: SHS exposure is an independent risk factor for psychological problems among children. Nonetheless, our study is unable to distinguish between fetal and child exposure to SHS.

Keywords: Secondhand smoke exposure, Psychological symptoms, Childhood, Population-based study

\section{Background}

Mental health disorders is the leading cause of healthrelated burden, representing for $15.5 \%$ of the disability adjusted life years in young people aged 10 to 24 years globally. [1] The prevalence of mental health disorders in children varies widely due to the heterogeneity in methodological and cultural factors; the estimated worldwide prevalence of mental health disorders is

\footnotetext{
*Correspondence: fanjiang@shsmu.edu.cn; junjimzhang@sina.com ${ }^{3}$ Department of Developmental and Behavioral Pediatrics, Shanghai Children's Medical Center Affiliated to Shanghai Jiao Tong University School of Medicine, Shanghai 200127, China

${ }^{1}$ MOE-Shanghai Key Laboratory of Children's Environmental Health, Xin Hua Hospital Affiliated to Shanghai Jiao Tong University School of Medicine, Shanghai 200092, China

Full list of author information is available at the end of the article
}

about 10 to $20 \%$ in children and is still increasing. [2] From a developmental perspective, childhood is being recognized as an important developmental transition stage during which many processes undergo substantial multi-dimensional changes including physiological, psychological and social. [3] Mental health disorders diagnosed in adulthood often originate in very early life. [4] Causal factors for mental health disorders are difficult to identify. Among the known or suspected risk factors, secondhand smoke (SHS) exposure is the major modifiable factor in the general population. [5] However, the mechanisms are still unclear. SHS exposure could be considered as an indicator for lower socio-economic status (SES), which in turn, is associated with poor mental health disorders. [6] The dopaminergic system could

(c) The Author(s). 2019 Open Access This article is distributed under the terms of the Creative Commons Attribution 4.0 International License (http://creativecommons.org/licenses/by/4.0/), which permits unrestricted use, distribution, and 
also be involved in the association between SHS exposure and mental health disorders and it is well established dopamine is an important neurotransmitter that controls many aspects of emotional, conduct and cognitive function. [7] Evidence from animal studies suggest that exposure to SHS increases dopamine release in brain areas such as caudate-putamen, nucleus accumbens and olfactory tubercle. [8] These brain areas are consistently demonstrated to be involved in emotional and behavioral regulation. [9]

Some previous studies have showed positive associations between SHS exposure and mental health disorders. [10-13] For example, one cross-sectional study in the US reported that a higher serum cotinine level increased the risk of depression, anxiety disorders, attention disorders and conduct problems after accounting for potential confounders among non-smoking children and adolescents. [10] However, another study has reported conflicting results in adults. [14]

Although smoke-free legislation has banned smoking in public areas in many parts of the world, this regulation is not applied to places such as homes or private cars. Smoking by parents or other household members are the primary source of child exposure to SHS. [15] In China, family structures are relatively complex, and the most common types are multigeneration and extended families. [16] About $40 \%$ of the world's tobacco was consumed in China. [17] Therefore, Chinese children are more likely to be exposed to SHS at home. As such, evidence from the Chinese context could be valuable. We examined this issue in a large population-based crosssectional survey, 'the Shanghai Child Health, Education and lifestyle Evaluation (SCHEDULE) study'. We also examined whether these associations varied by sex.

\section{Methods}

\section{Data source}

The SCHEDULE study is a cross-sectional populationbased survey in Shanghai, China, in June 2014. Detailed description is provided elsewhere. [18, 19] Briefly, seven districts were randomly selected from a total of 19 districts in Shanghai. Among these selected districts, 26 primary schools were randomly chosen. All students from grades one to five in the chosen schools were eligible for participation in this study. For schools with fewer than 1000 students, all of them were eligible, whereas in schools with over 1000 students, only half of the classes were randomly selected. All the students in the selected classes were eligible for this study. An invitation letter and a consent form were sent to the parents of the eligible students to inform them of the study and invite them to participate. If the parents or guardians agreed to join, they were asked to complete a selfadministered questionnaire. Collected was information on parental demographic characteristics (parental education level and family income), perinatal characteristics of the index child (gestational age at birth, sex, mode of birth (vaginal delivery/caesarean delivery) and birth weight), SHS exposure status and offspring characteristics (medical history, food intake frequency, physical activity and mental health disorders during childhood). Anthropometric measures including weight and height were collected by trained researchers.

\section{Exposure}

SHS exposure was reported by parents via the following questions: Is the child exposed to tobacco in private or public areas? and if yes: how long is the child exposed to SHS daily $(<1 \mathrm{~h} /$ day, $1-2 \mathrm{~h} /$ day and $\geq 3 \mathrm{~h} /$ day).

\section{Outcome}

Psychological symptoms were assessed by the Strengths and Difficulties Questionnaires (SDQ) reported by parents in our study. [20] SDQ consists of a set of 25 items concerning the five most important domains of child behavioral and emotional problems including emotional symptoms, conduct problems, hyperactivity-inattention, peer problems and prosocial behavior. Each domain has 5 items, with each item scored 0 for not true, 1 for somewhat true, 2 for certainly true. The total difficulty score is the sum of the first four subscale scores (emotional symptoms, conduct problems, hyperactivityinattention, peer problems), ranging from 0 to 40 with higher scores indicating more difficulties. The fifth subscale, i.e., prosocial behavior, describes positive attributes of the children. For this domain, the reverse coding was applied. SDQ has different language versions. The Chinese version of SDQ has the same structure as that in other languages and good reliability and validity. It has been widely used in China. [21] According to cut-off points recommended and widely used in China, [20-22] SDQ total and its subscales scores were classified into two groups as 'abnormal' and 'normal', and then subsequently categorized into "abnormal", "borderline" and "normal" groups. Children classified into the "abnormal" group indicated that they have substantial risk of probable psychological symptoms. [21]

\section{Statistical analysis}

Baseline characteristics by SHS exposure were compared using Pearson's $X^{2}$ tests and analysis of covariance. Multivariable logistic regression was used to examine the adjusted associations of SHS exposure with total SDQ score and its specific domains in children. Whether the associations varied by sex was assessed based on the significance of interaction terms using likelihood ratio tests. A dose-response association was tested for linear trends across groups. 
We select potential confounders that were associated with both exposure (i.e., SHS exposure) and outcomes (i.e., psychiatric symptoms). To illustrate the role of possible confounding, we present two models. Model 1 adjusted for sex and child age when the survey was conducted. Model 2 additionally adjusted for parental education, household income, mode of birth, place of birth and body mass index z-score (relative to the 2007 World Health Organization growth reference). [23]

Multiple imputation was used for missing exposures (SHS exposure was imputed for 5.4\%) and confounders (paternal education imputed for 5.6\%, maternal education for $6.4 \%$, family income for $32.1 \%$, mode of birth $9.3 \%$, place of birth for $11.8 \%)$. Multiple imputation was specified based on a flexible additive regression with predictive mean matching incorporating information on all these factors including outcomes, exposures and other covariates (sex, child age when the survey was conducted, parental education, family income, place of birth, mode of birth and maternal gestational diabetes). [24] We summarized the results from 10 imputed datasets into single estimated odds ratio (OR) with confidence intervals (CI) adjusted for missing data uncertainty.

Finally, we conducted a sensitivity analysis using ordinal logistic regression model when psychological symptoms was categorized into three groups i.e. "normal", "borderline" and "abnormal" to check for consistency. We also performed complete case analysis for comparison.

Data were analyzed using Stata version 13 (Stata Corp, College Station, Texas, USA) and R V.3.3.3 (R development Core Team, Vienna, Austria).

\section{Ethics approval}

The SCHEDULLE study obtained ethical approval from the Institutional Review Board of the Shanghai Children's Medical Center.

\section{Results}

A total of 17,571 students participated in this population-based survey with the participation rate $99.7 \%$. Of these 17,571, 15,344 participants had parentreported SDQ scores measured at 6 13 ages and 10.9\% had a psychological problem. Table 1 shows the total and the five domains of SDQ characteristics of these participants.
Table 2 presents unadjusted associations between SHS exposure and potential confounders. Among the 15,344 participants, $20.9 \%$ children were not habitually exposed to SHS; $63.0 \%$ were exposed to SHS for $<1 \mathrm{~h} /$ day, $10.4 \%$ for $1-2 \mathrm{~h} /$ day, $5.7 \%$ for $\geq 3 \mathrm{~h} /$ day. Compared to children from low SES families, children from higher SES families are less prone to SHS exposure. SHS exposure was higher in children born in Shanghai than those born in other places across China. Higher SHS exposure level was associated with higher BMI.

Table 3 shows the estimates of the contribution of SHS exposure to total SDQ score and its five specific domains. Compared to children without exposure, almost any duration of SHS exposure was associated with the total SDQ score: OR 1.42, 95\% CI 1.22 to 1.66 for SHS exposure $<1 \mathrm{~h} /$ day, OR $2.14,95 \%$ CI 1.76 to 2.62 for $1-$ $2 \mathrm{~h} /$ day and OR $2.53,95 \%$ CI 2.01 to 3.18 for $\geq 3 \mathrm{~h} /$ day after adjusting for sex and age. Likewise, any duration of SHS exposure were associated with five specific SDQ domains: emotional symptoms, conduct problems, hyperactivity-inattention, peer problems and prosocial behavior. After further adjustment for family SES, mode of birth, place of child birth and child BMI z-score, the associations for total SDQ score and other specific domains were attenuated slightly but remained significant. These associations did not vary by sex ( $p$ value for sex interaction 0.34 for general psychological problems, 0.97 for emotional symptoms, 0.68 for conduct problems, 0.79 for hyperactivity-inattention, 0.43 for peer relationship problems and 0.07 for prosocial behavior). The dose-response relationship was observed across the SHS exposure group ( $p$ value for linear trend $<0.001$ ).

When we used ordinal logistic regression, the results remained the same (Table 4). The proportional odds assumption for the SHS exposure was not violated with $p$ values for likelihood ratio test ranging from 0.06 to 0.92 . Complete case analysis showed a similar result (Additional file 1: Table S1).

\section{Discussion}

In this large population-representative study, we found that children who were exposed to any duration of SHS had a higher risk of having psychological symptoms and its specific domains concerning emotional symptoms, conduct problems, hyperactivity-inattention, peer relationship problems and prosocial behaviors than those

Table 1 Description of psychological symptoms among children in the SCHEDULE study in China

\begin{tabular}{lllllll}
\hline & Total SDQ score & Emotional symptoms & Conduct problems & Hyperactivity-attention & Peer-problems & Prosocial behavior \\
\hline \multirow{2}{*}{ Normal } & $\mathrm{N}(\%)$ & $\mathrm{N}(\%)$ & $\mathrm{N}(\%)$ & $\mathrm{N}(\%)$ & $\mathrm{N}(\%)$ & $\mathrm{N}(\%)$ \\
Borderline & $11,678(76.1)$ & $12,928(84.3)$ & $12,258(79.9)$ & $10,775(70.2)$ & $7745(50.5)$ & $12,396(81.6)$ \\
Abnormal & $1995(13.0)$ & $1217(7.9)$ & $1806(11.8)$ & $1616(10.5)$ & $3281(21.4)$ & $1680(11.1)$ \\
\hline
\end{tabular}


Table 2 Baseline characteristics by secondhand smoke exposure from the SCHEDULE study in China

\begin{tabular}{|c|c|c|c|c|c|c|}
\hline \multicolumn{7}{|c|}{ Secondhand smoke exposure/daily, $\%^{\mathrm{a}}$} \\
\hline Characteristics & & None & $<1 \mathrm{~h}$ & $1-2 h$ & $\geq 3 \mathrm{~h}$ & $p$ value \\
\hline & $N(\%)$ & 20.8 & 63.1 & 10.5 & 5.6 & \\
\hline Sex & & & & & & 0.968 \\
\hline Boys & $9242(53.8)$ & 53.8 & 53.4 & 53.6 & 54.0 & \\
\hline Girls & $7943(46.2)$ & 46.2 & 46.6 & 46.4 & 46.0 & \\
\hline Age (Mean score) & & 9.1 & 9.2 & 9.2 & 9.2 & 0.55 \\
\hline Household income & & & & & & $<0.001$ \\
\hline$\leq 30,000$ & $1564(13.1)$ & 9.1 & 13.4 & 16.1 & 13.3 & \\
\hline $30,000-100,000$ & $5306(44.5)$ & 35.2 & 46.6 & 48.4 & 44.7 & \\
\hline $100,000-300,000$ & $4190(35.1)$ & 42 & 34.3 & 30.6 & 35.2 & \\
\hline$\geq 300,000$ & $864(7.3)$ & 13.7 & 5.7 & 4.9 & 6.8 & \\
\hline Maternal education & & & & & & $<0.001$ \\
\hline $\begin{array}{l}\text { Middle school or } \\
\text { below }\end{array}$ & $5594(34.0)$ & 24.9 & 36.3 & 37.1 & 29.3 & \\
\hline High school & $4386(26.7)$ & 22.1 & 27.4 & 30.5 & 30.1 & \\
\hline College or above & 6467 (39.3) & 53.0 & 36.4 & 32.4 & 40.6 & \\
\hline Paternal education & & & & & & $<0.001$ \\
\hline $\begin{array}{l}\text { Middle school or } \\
\text { below }\end{array}$ & $4834(29.1)$ & 19.4 & 31.1 & 34.5 & 25.8 & \\
\hline High school & $5005(30.2)$ & 23.3 & 31.8 & 33.7 & 34.1 & \\
\hline College or above & $6743(40.7)$ & 57.3 & 37.1 & 31.8 & 40.1 & \\
\hline Mode of birth & & & & & & 0.06 \\
\hline Vaginal & $8012(50.2)$ & 48.8 & 50.3 & 52.5 & 48.4 & \\
\hline Cesarean & $7933(49.8)$ & 51.2 & 49.7 & 47.5 & 51.6 & \\
\hline Place of birth & & & & & & $<0.001$ \\
\hline Shanghai & $8096(52.2)$ & 48.8 & 52.9 & 55.0 & 57.4 & \\
\hline Others & $7402(47.8)$ & 51.2 & 47.1 & 45.0 & 42.6 & \\
\hline $\begin{array}{l}\text { BMI z-score } \\
\text { (Mean score) }\end{array}$ & & 0.21 & 0.30 & 0.30 & 0.38 & 0.01 \\
\hline
\end{tabular}

who were not exposed to SHS after adjustment for potential confounders.

Our findings are consistent with most previous studies showing that children exposed to SHS had increased risks of general psychological symptoms and specific domains of psychological symptoms. [10, 11, 13, 25-27] Two studies have reported there existed a positive doseresponse relationship between SHS exposure and psychological symptoms. [13, 27] Our results showing that SHS exposure associated with psychological symptoms concerning hyperactivity-inattention problems domain, are in line with another study using DSM-IV diagnosis criteria for attention deficit and hyperactivity disorder. [28] Our findings are partly consistent with two longitudinal studies which demonstrated that children exposed to pre- and postnatal tobacco were at remarkably increased risk of being classified as abnormal assessed by SDQ scale, although the SHS exposure during pregnancy seems to play a stronger role. [12, 29]

Despite that our study is a large population-based study with cluster random probability sampling, it has some limitations. First, SHS exposure was reported by parents, which was subject to inaccuracy and misclassification. However, a previous study conducted among school children confirmed that questionnaires reported by parents could provide a valid estimate of SHS exposure when comparing to serum cotinine levels. [30] Furthermore, underestimation of actual exposure could only make these estimates conservative. Meanwhile, we could not rule out the possibility that parents of children having psychological symptoms might have overreported SHS exposure which could overestimate the association. Second, as in other epidemiological studies, psychological symptoms were assessed by questionnaire rather than clinical diagnostics. However, SDQ is a reliable scale which has been validated and widely used in China. [21] Still, the presence of abnormal defined by SDQ scores is a good predictor of diagnosed mental health disorders. [31] Third, it is possible that our results might be affected by unmeasured factors such as parents' mental health disorders, although we had controlled for several confounders. Parents' mental health disorders might also play a role in the development of mental health disorders in offspring during childhood. [32] Fourth, the nature of these data are cross-sectional. Although causal inference could not be established, the direction between SHS exposure and psychological symptoms is robust. Fifth, missing data are inevitable in the large populationbased study even though the percentage of missing is not very high. However, multiple imputation was used for missing exposures and confounders in the model to increase statistical power. [24] Sixth, we do not have information on children's lifestyle (i.e., smoking or alcohol use). Children with higher SHS exposure are more likely to initiate smoke or drink. Inability to control for these confounders might overestimate our associations. However, in China, the prevalence of smoking among primary school students are very lower (less than $0.2 \%$ ). [33] Lastly, the association between SHS exposure and worse psychological outcomes among children could be explained in part by prenatal exposure to tobacco. [34] Unfortunately, the lack of prenatal tobacco exposure measurement prevented us from examining this impact. For maternal SHS from home sources, due to the fact that smoking behavior is often difficult to change, children who are exposed to SHS at home are likely to have been exposed to SHS in utero. In these cases, due to the high correlation between in utero and postnatal exposure to SHS, [34] the observed association remains true. In cases where maternal SHS exposure was from the 
Table 3 Adjusted associations of secondhand smoke exposure with psychological symptoms using multiple imputation in the SCHEDULE study in China

\begin{tabular}{|c|c|c|c|c|}
\hline & \multicolumn{4}{|c|}{ Secondhand smoke exposure } \\
\hline & None & $<1 \mathrm{~h} /$ daily & 1-2 h/daily & $\geq 3$ h/daily \\
\hline & Reference & OR (95\% Cl) & OR (95\% Cl) & OR (95\% Cl) \\
\hline \multicolumn{5}{|l|}{ Model 1} \\
\hline Total SDQ score & 1 & $1.60(1.38$ to 1.86$)$ & 2.44 (2.02 to 2.96$)$ & 2.75 (2.20 to 3.43$)$ \\
\hline Emotional symptoms & 1 & $1.49(1.26$ to 1.76$)$ & 1.98 (1.59 to 2.48$)$ & $2.16(1.66$ to 2.81$)$ \\
\hline Conduct problems & 1 & $1.46(1.24$ to 1.72$)$ & 2.03 (1.64 to 2.52$)$ & 2.20 (1.71 to 2.83$)$ \\
\hline Hyperactivity-inattention & 1 & $1.37(1.22$ to 1.53$)$ & 1.79 (1.53 to 2.09$)$ & 2.14 (1.79 to 2.57$)$ \\
\hline Peer relationship problems & 1 & $1.46(1.33$ to 1.61$)$ & $1.70(1.48$ to 1.94$)$ & $1.52(1.29$ to 1.80$)$ \\
\hline Prosocial behaviors & 1 & 1.17 (0.99 to 1.38$)$ & 1.34 (1.06 to 1.68$)$ & $1.46(1.11$ to 1.91$)$ \\
\hline \multicolumn{5}{|l|}{ Model 2} \\
\hline Total SDQ score & 1 & $1.42(1.22$ to 1.66$)$ & 2.14 (1.76 to 2.62$)$ & 2.53 (2.01 to 3.18$)$ \\
\hline Emotional symptoms & 1 & $1.38(1.16$ to 1.64$)$ & 1.84 (1.46 to 2.31$)$ & 2.05 (1.57 to 2.68$)$ \\
\hline Conduct problems & 1 & $1.36(1.15$ to 1.61$)$ & $1.88(1.50$ to 2.34$)$ & 2.09 (1.61 to 2.70$)$ \\
\hline Hyperactivity-inattention & 1 & $1.24(1.10$ to 1.39$)$ & $1.58(1.35$ to 1.86$)$ & 1.98 (1.65 to 2.38$)$ \\
\hline Peer relationship problems & 1 & 1.25 (1.13 to 1.38$)$ & $1.41(1.23$ to 1.63$)$ & $1.36(1.14$ to 1.61$)$ \\
\hline Prosocial behaviors & 1 & $1.06(0.90$ to 1.26$)$ & 1.14 (0.89 to 1.44$)$ & 1.37 (1.03 to 1.82$)$ \\
\hline
\end{tabular}

Model 1 adjusted for sex, age at measurement;

Model 2 additionally adjusted for parents' education, household income, mode of birth, place of birth and BMI z-score (relative to the 2007 World Health

Organization growth reference)

Table 4 Adjusted associations of secondhand smoke exposure with psychological symptoms obtained from proportional odds model in the SCHEDULE study in China

\begin{tabular}{|c|c|c|c|c|}
\hline & \multicolumn{4}{|c|}{ Secondhand smoke exposure } \\
\hline & None & $<1$ h/daily & 1-2 h/daily & $\geq 3$ h/daily \\
\hline & Reference & pOR $(95 \% \mathrm{Cl})$ & pOR (95\% Cl) & pOR $(95 \% \mathrm{Cl})$ \\
\hline \multicolumn{5}{|l|}{ Model 1} \\
\hline Total SDQ score & 1 & $1.63(1.47$ to 1.81$)$ & 2.30 (2.00 to 2.65$)$ & 2.46 (2.08 to 2.92 ) \\
\hline Emotional symptoms & 1 & 1.41 (1.25 to 1.59$)$ & 1.94 (1.65 to 2.28$)$ & 1.75 (1.43 to 2.13$)$ \\
\hline Conduct problems & 1 & $1.40(1.26$ to 1.57$)$ & 1.88 (1.63 to 2.19$)$ & 1.90 (1.59 to 2.28 ) \\
\hline Hyperactivity-inattention & 1 & 1.38 (1.26 to 1.52$)$ & 1.87 (1.64 to 2.13$)$ & 2.08 (1.77 to 2.44$)$ \\
\hline Peer relationship problems & 1 & 1.45 (1.36 to 1.59$)$ & 1.73 (1.54 to 1.94$)$ & 1.53 (1.33 to 1.77$)$ \\
\hline Prosocial behaviors & 1 & $1.28(1.15$ to 1.43$)$ & 1.48 (1.26 to 1.73$)$ & 1.31 (1.07 to 1.59$)$ \\
\hline \multicolumn{5}{|l|}{ Model 2} \\
\hline Total SDQ score & 1 & 1.47 (1.28 to 1.70$)$ & 1.98 (1.63 to 2.40$)$ & 2.28 (1.81 to 2.87 ) \\
\hline Emotional symptoms & 1 & 1.29 (1.10 to 1.53$)$ & 1.84 (1.48 to 2.28$)$ & 1.63 (1.24 to 2.14$)$ \\
\hline Conduct problems & 1 & $1.40(1.26$ to 1.57$)$ & 1.88 (1.63 to 2.19$)$ & 1.90 (1.59 to 2.28$)$ \\
\hline Hyperactivity-inattention & 1 & 1.20 (1.06 to 1.37$)$ & $1.52(1.28$ to 1.81$)$ & 1.99 (1.61 to 2.47$)$ \\
\hline Peer relationship problems & 1 & 1.31 (1.17 to 1.46$)$ & 1.44 (1.23 to 1.69$)$ & 1.52 (1.25 to 1.85$)$ \\
\hline Prosocial behaviors & 1 & 1.22 (1.05 to 1.42$)$ & $1.42(1.15$ to 1.76$)$ & 1.35 (1.03 to 1.77$)$ \\
\hline
\end{tabular}

Model 1 adjusted for sex, age at measurement;

Model 2 additionally adjusted for parents' education, household income, mode of birth, place of birth and BMI z-score (relative to the 2007 World Health Organization growth reference) 
workplace, fetal exposure may have occurred but the child may not be exposed to SHS. Taking all these scenarios into account, the association between child SHS exposure and psychological symptoms in our study is likely to be underestimate. Nonetheless, our study is unable to distinguish between fetal and child exposure to SHS. Pre-and postnatal exposure to tobacco are highly correlated and difficult to differentiate. [34]

Several potential mechanisms may explain our findings. First, nicotine, the main psychoactive component in tobacco, can exert neurotoxic effects on developing brain areas involved in emotional processing. [35] Nicotine exposure mediates the acetylcholine receptor through activating and desensitizing neuronal nicotinic acetylcholine receptors (nAChRs). [35] During primary school years, children's brain are still undergoing dramatic changes which are vulnerable to the harmful effect of nicotine exposure. [36] Second, catecholaminergic neurotransmitter systems may also provide a link between SHS exposure and psychological symptoms. The activation of nicotinic acetylcholine receptors can affect the catecholaminergic neurotransmitter system and the level of catecholamine dopamine and noradrenaline in the prefrontal cortex and independently regulate attention and behavioral symptoms. [37] Third, the observed estimation between SHS exposure and psychological symptoms could be explained by the passive geneenvironmental correlation. [38] For example, mothers who pass down the genetic variants for psychological symptoms to their children might also have an increased risk of being exposed to SHS. SHS exposure could more likely to be considered as genetic risk that parents transmit to children rather than a risk factor for a child's psychological symptoms. Fourth, we cannot rule out the possibility that the observed associations could be due to residual confounding by SES, other uncontrolled confounding such as unhealthy lifestyles, or fewer social and psychological resources available or the biological effect of SHS. [39] Furthermore, in-utero tobacco exposure might also play a role in the association. [40] Several studies have found that children exposed to tobacco during the prenatal period have increased risk of developing more behavioral and emotional problems. [41-43]

\section{Conclusion}

In summary, our study has confirmed previous studies showing SHS exposure is associated with more psychological symptoms among children. Even though we could not rule out the possibility that prenatal exposure to SHS might also contribute to the observed associations, our result has important public health implications. Children's psychological symptoms has constituted a global epidemic. Identifying modifiable risk factors will facilitate effective prevention strategies. Smoke free policy is the most effective way to reduce SHS exposure at public and private places. Efforts to restrict SHS exposure in public places or homes where children are present could provide a perspective to alleviate the heavy burden of diseases attributable to cigarette smoking. Our findings could be used to inform future SHS control policies and reinforce the need for public education campaigns. These campaigns could be implemented to raise the public awareness of the harmful psychological effect of SHS exposure.

\section{Additional file}

Additional file 1: Table S1. Adjusted associations of secondhand smoke exposure with psychological symptoms in the SCHEDULE study in China. (DOCX $16 \mathrm{~kb})$

\section{Abbreviations}

Cl: Confidence intervals; SCHEDULE: Shanghai Children's Health, Education and Lifestyle Evaluation; SD: Standard deviations; SDQ: Strengths and Difficulties Questionnaire; SES: Socio-economic status; SHS: Secondhand smoke; WHO: World Health Organization

\section{Acknowledgements \\ We thank all the participants included in the study.}

\section{Authors' contributions}

HW preformed the literature review, conducted data analysis and drafted the manuscript. YTZ and FL contributed to the interpretation of the data, critically revising the paper and approval of the final version. JZ and FJ are the guarantors. They developed the study conception, directed the analytic strategy of the study and supervised the drafting of the manuscript. All authors approved the final manuscript as submitted and agree to be accountable for all aspects of the work.

\section{Funding}

This work was supported by grants from Shanghai Municipal Commission of Health and Family Planning (Key Program, No.2017ZZ02026; Developing Plan of Important Weak Disciplines, No.2016ZB0103; and No.20164Y0095); the Fourth Round of Three-Year Public Health Action Plan (2015-2017) (GWIV36), the National Natural Science Foundation of China (No. 81602870; No. 81602868; No. 81728017); Shanghai Science and Technology Commission of Shanghai Municipality (No.17411965300). The funders had no role in the study design, data collection, analysis or interpretation of data, decision to publish, or preparation of the manuscript.

\section{Availability of data and materials}

The datasets used and/or analyzed during the current study are available from the corresponding author on reasonable request.

Ethics approval and consent to participate

The study obtained an ethical approval from the Institutional Review Boards of the Shanghai Children's Medical Center affiliated to Shanghai Jiao Tong University School of Medicine. Written informed consents were obtained from all the participants in this study.

Consent for Publication

Not applicable.

Competing interests

The authors declare that they have no competing interests.

\section{Author details}

${ }^{1}$ MOE-Shanghai Key Laboratory of Children's Environmental Health, Xin Hua Hospital Affiliated to Shanghai Jiao Tong University School of Medicine, Shanghai 200092, China. ${ }^{2}$ Child Health Advocacy Institute, Shanghai 
Children's Medical Center Affiliated to Shanghai Jiao Tong University Schoo of Medicine, Shanghai 200127, China. ${ }^{3}$ Department of Developmental and Behavioral Pediatrics, Shanghai Children's Medical Center Affiliated to Shanghai Jiao Tong University School of Medicine, Shanghai 200127, China.

\section{Received: 7 September 2018 Accepted: 17 May 2019}

Published online: 10 July 2019

\section{References}

1. Gore FM, Bloem PJ, Patton GC, Ferguson J, Joseph V, Coffey C, Sawyer SM, Mathers CD. Global burden of disease in young people aged 10-24 years: a systematic analysis. Lancet. 2011;377(9783):2093-102.

2. Costello EJ, Egger H, Angold A. 10-year research update review: the epidemiology of child and adolescent psychiatric disorders: I. methods and public health burden. J Am Acad Child Adolesc Psychiatry. 2005;44(10):972-86.

3. Kuh D, Ben-Shlomo Y, Lynch J, Hallqvist J, Power C. Life course epidemiology. J Epidemiol Community Health. 2003;57(10):778-83.

4. Kessler RC, Amminger GP, Aguilar-Gaxiola S, Alonso J, Lee S, Ustun TB. Age of onset of mental disorders: a review of recent literature. Curr Opin Psychiatry. 2007;20(4):359.

5. Ziedonis D, Hitsman B, Beckham JC, Zvolensky M, Adler LE, AudrainMcGovern J, Breslau N, Brown RA, George TP, Williams J. Tobacco use and cessation in psychiatric disorders: National Institute of Mental Health report. Nicotine Tob Res. 2008;10(12):1691-715.

6. Bradley RH, Corwyn RF. Socioeconomic status and child development. Annu Rev Psychol. 2002:53(1):371-99.

7. Bandiera FC. What are candidate biobehavioral mechanisms underlying the association between secondhand smoke exposure and mental health? Med Hypotheses. 2011;77(6):1009-10.

8. Bahk J, Li S, Park M, Kim M. Dopamine D1 and D2 receptor mRNA upregulation in the caudate-putamen and nucleus accumbens of rat brains by smoking. Prog Neuro-Psychopharmacol Biol Psychiatry. 2002;26(6):1095-104.

9. Tekin S, Cummings JL. Frontal-subcortical neuronal circuits and clinical neuropsychiatry: an update. J Psychosom Res. 2002;53(2):647-54.

10. Bandiera FC, Richardson AK, Lee DJ, He J-P, Merikangas KR. Secondhand smoke exposure and mental health among children and adolescents. Arch Pediatr Adolesc Med. 2011;165(4):332-8.

11. Eskenazi B, Castorina R. Association of prenatal maternal or postnatal child environmental tobacco smoke exposure and neurodevelopmental and behavioral problems in children. Environ Health Perspect. 1999;107(12):991.

12. Tiesler CM, Chen C-M, Sausenthaler S, Herbarth O, Lehmann I, Schaaf $B$, Krämer U, von Berg A, von Kries R, Wichmann H-E. Passive smoking and behavioural problems in children: results from the LISAplus prospective birth cohort study. Environ Res. 2011;111(8):1173-9.

13. Padron A, Galan I, Garcia-Esquinas E, Fernandez E, Ballbe M, RodriguezArtalejo F. Exposure to secondhand smoke in the home and mental health in children: a population-based study. Tob Control. 2016;25(3):307-12.

14. Bot M, Vink JM, Willemsen G, Smit JH, Neuteboom J, Kluft C, Boomsma DI, Penninx BW. Exposure to secondhand smoke and depression and anxiety: a report from two studies in the Netherlands. J Psychosom Res. 2013;75(5):431-6.

15. King K, Martynenko M, Bergman MH, Liu Y-H, Winickoff JP, Weitzman M. Family composition and Children9s exposure to adult smokers in their homes. Pediatrics. 2009;123(4):e559-64.

16. Yi Z. A demographic analysis of family households in China, 1982-1995. J Comp Fam Stud. 2002;33(1):15-34.

17. Furlow B. China's tobacco control--and the tobacco monopoly. Lancet Respir Med. 2016;4(1):12.

18. Chen C, Zhang Y, Sun W, Chen Y, Jiang Y, Song Y, Lin Q, Zhu L, Zhu Q, Wang $X$. Investigating the relationship between precocious puberty and obesity: a cross-sectional study in Shanghai, China. BMJ Open. 2017:7(4):e014004.

19. Chu S, Zhang Y, Jiang Y, Sun W, Zhu Q, Wang B, Jiang F, Zhang J. Cesarean section without medical indication and risks of childhood allergic disorder, attenuated by breastfeeding. Sci Rep. 2017;7(1):9762.

20. Goodman R. Psychometric properties of the strengths and difficulties questionnaire. J Am Acad Child Adolesc Psychiatry. 2001;40(11):1337-45.

21. Du Y, Kou J, Coghill D. The validity, reliability and normative scores of the parent, teacher and self report versions of the strengths and difficulties questionnaire in China. Child Adolesc Psychiatry Ment Health. 2008;2(1):8.

22. Zhang $Y$, Zhang D, Li X, Ip P, Ho F, Jiang Y, Sun W, Zhu Q, Zhu W, Zhang J, et al. Daily time-use patterns and obesity and mental health among primary school students in Shanghai: a population-based cross-sectional study. Sci Rep. 2017;7(1):16200

23. Onis Md OAW, Borghi E, Siyam A, Nishida C, Siekmann J. Development of a WHO growth reference for school-aged children and adolescents. Bull World Health Organ. 2007:85:660-7.

24. Schafer JL. Multiple imputation: a primer. Stat Methods Med Res. 1999:8(1):3-15.

25. Hamer M, Ford T, Stamatakis E, Dockray S, Batty GD. Objectively measured secondhand smoke exposure and mental health in children: evidence from the Scottish health survey. Arch Pediatr Adolesc Med. 2011;165(4):326-31.

26. Chastang J, Baïz N, Cadwallader J, Cadwalladder J, Robert S, Dywer J, Dywer J, Charpin D, Caillaud D, de Blay F, et al. Postnatal environmental tobacco smoke exposure related to behavioral problems in children. PLoS One. 2015;10(8):e0133604

27. Twardella D, Bolte G, Fromme H, Wildner M, von Kries R. Exposure to secondhand tobacco smoke and child behaviour - results from a cross-sectional study among preschool children in Bavaria. Acta Paediatr. 2010;99(1):106-11.

28. Milberger S, Biederman J, Faraone SV, Chen L, Jones J. Is maternal smoking during pregnancy a risk factor for attention deficit hyperactivity disorder in children? Am J Psychiatry. 1996;153(9):1138.

29. Rodriguez A, Bohlin G. Are maternal smoking and stress during pregnancy related to ADHD symptoms in children? J Child Psychol Psychiatry. 2005; 46(3):246-54.

30. Avila-Tang E, Elf JL, Cummings KM, Fong GT, Hovell MF, Klein JD, McMillen R, Winickoff JP, Samet JM. Assessing secondhand smoke exposure with reported measures. Tob Control. 2013;22(3):156-63.

31. Woerner W, Fleitlich-Bilyk B, Martinussen R, Fletcher J, Cucchiaro G, Dalgalarrondo P, Lui M, Tannock R. The strengths and difficulties questionnaire overseas: evaluations and applications of the SDQ beyond Europe. Eur Child Adolesc Psychiatry. 2004;13:ii47-54

32. Braun JM, Kahn RS, Froehlich T, Auinger P, Lanphear BP. Exposures to environmental toxicants and attention deficit hyperactivity disorder in US children. Environ Health Perspect. 2006;114(12):1904

33. Zhu BP, Liu M, Shelton D, Liu S, Giovino GA. Cigarette smoking and its risk factors among elementary school students in Beijing. Am J Public Health. 1996;86(3):368-75.

34. Rückinger S, Rzehak P, Chen C-M, Sausenthaler S, Koletzko S, Bauer C-P, Hoffmann U, Kramer U, Berdel D, Von Berg A. Prenatal and postnatal tobacco exposure and behavioral problems in 10-year-old children: results from the GINI-plus prospective birth cohort study. Environ Health Perspect. 2010;118(1):150

35. Dwyer JB, McQuown SC, Leslie FM. The dynamic effects of nicotine on the developing brain. Pharmacol Ther. 2009;122(2):125-39.

36. Goriounova NA, Mansvelder HD. Short-and long-term consequences of nicotine exposure during adolescence for prefrontal cortex neuronal network function. Cold Spring Harb Perspect Med. 2012;2(12):a012120.

37. Arnsten AF. Toward a new understanding of attention-deficit hyperactivity disorder pathophysiology: an important role for prefrontal cortex dysfunction. CNS Drugs. 2009:23(Suppl 1):33-41.

38. Jaffee SR, Price TS. Gene-environment correlations: a review of the evidence and implications for prevention of mental illness. Mol Psychiatry. 2007;12(5):432.

39. Bolte G, Fromme H, Group GS. Socioeconomic determinants of children's environmental tobacco smoke exposure and family's home smoking policy. Eur J Pub Health. 2008;19(1):52-8.

40. Cornelius M, Day N. Developmental consequences of prenatal tobacco exposure. Curr Opin Neurol. 2009;22(2):121-5.

41. Tanaka K, Miyake Y, Furukawa S, Arakawa M. Perinatal smoking exposure and behavioral problems in Japanese children aged 5 years: the Kyushu Okinawa maternal and child health study. Environ Res. 2016;151:383-8.

42. Leung C, Leung G, Schooling C. Early second-hand smoke exposure and child and adolescent mental health: evidence from Hong Kong's 'Children of 1997' birth cohort. Addiction. 2015:110(11):1811-24.

43. Quinn P, Rickert M, Weibull C, Johansson A, Lichtenstein P, Almqvist C, Larsson $\mathrm{H}$, lliadou A, D'Onofrio B. Association between maternal smoking during pregnancy and severe mental illness in offspring. JAMA Psychiatry. 2017;74(6):589-96.

\section{Publisher's Note}

Springer Nature remains neutral with regard to jurisdictional claims in published maps and institutional affiliations. 